\title{
INVESTIGATING THE PERFORMANCE OF VISCOELASTIC DAMPERS (VED) UNDER NEAR- FIELD EARTHQUAKES WITH DIRECTIVITY FEATURE
}

\author{
Ali VATANSHENAS ${ }^{1,{ }^{*},}$, Mohammad Sadegh ROHANIMANESH ${ }^{2}$, Ehsan \\ MOHAMMADIHA ${ }^{1}$ \\ ${ }^{1}$ Engineering Faculty, Islamic Azad University, Central Tehran Branch, Tehran, Iran. \\ 2 Department of Civil Engineering, Faculty of Technology and Engineering, Islamic Azad University, \\ Central Tehran Branch, Tehran, Iran. \\ corresponding author: a.vatanshenas@gmail.com.
}

\section{Abstract}

One of the most important factors that make structures vulnerable to earthquakes is the short distance between structures and epicenter. Near-field earthquakes have special properties, such as increasing acceleration applied to the structure, which distinguishes them from far-field earthquakes. Therefore, the absorption of input energy for structures located near the faults is very important. Hence, by rotating the earthquake acceleration time history and comparing the resulting spectral acceleration response, the angle which applies the greatest force to the structure on the earthquake directivity side is obtained, and then the performance of a steel structure with viscoelastic dampers (VED) under near-field earthquakes with directivity feature is investigated. After analyzing the structure using nonlinear time history analysis, it was observed that the directivity phenomenon leads to significant increase in the force applied to the structure, but the viscoelastic dampers showed an acceptable performance in both states of with and without directivity.
\end{abstract}

\section{Keywords:}

Directivity effect;

Near-field earthquake;

Steel structure;

Viscoelastic damper;

Vibration control.

\section{Introduction}

The amount of energy which enters the structure depends on several factors such as the duration of the earthquake and its frequency content, the location of the structure and its stiffness and mass. Absorption of energy by lateral force resisting systems determines the performance of a structure during an earthquake. The use of dampers is one of the methods to reduce the damage to structural members due to the yielding of these members. Generally, the dampers are divided into two groups of speed-dependent and displacement-dependent dampers. In this classification, the viscoelastic damper is considered as a speed-dependent damper (Fig. 1). Some of the most important advantages of this type of dampers include easy installation, cost reduction and also the proper performance during an earthquake over a wide range of ambient temperature.

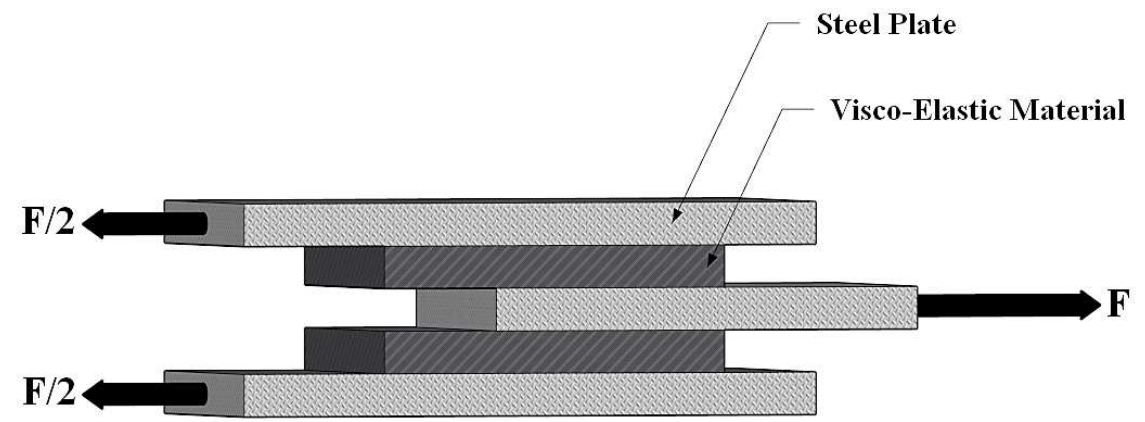

Fig. 1: Schematic diagram of a viscoelastic damper. 
Cox and Ashford (2002) [1] defined near-field earthquakes as earthquakes recorded by seismograph within a distance of less than $10 \mathrm{~km}$ from the fault and near-field refers to the regions where their distance to fault is less than $10 \mathrm{~km}$., but Wang et al. (2002) [2] have determined this value to $20 \mathrm{~km}$ for the near-field regions. Bertero et al. (1978) [3] during a study, stated that near-field earthquakes could increase structural responses. A study was also conducted by Chopra and Chintanapakdee (2001) [4] on a single degree of freedom (SDOF) system, which indicated that for a certain amount of ductility, the needed resistance under the far-field earthquake records is less than the near-field earthquake records. Somerville et al. (1997) [5] also reported that in the near-field earthquakes, the energy caused by the earthquake can be determined in form of a large pulse at the beginning of the earthquake record. According to a study provided by Ghobarah (2004) [6], the acceleration-time graphs recorded in near-field regions are richer in frequency content than far-field regions, i.e. it includes a greater range of frequencies, and contrary to far-field regions, the higher frequencies did not disappear because of the adjacency to the fault. When an earthquake occurs with directivity feature, it means that the acceleration exceeds the expected value in the near-field region. This study was carried out aimed to investigate the performance of the viscoelastic damper system under near-field earthquakes with directivity feature.

\section{Determining viscoelastic damper specifications}

The viscoelastic material of $3 \mathrm{M}$ ISD 110 was used to determine viscoelastic dampers specifications. This material has a loss factor of $\eta_{v}=1.2$, storage modulus of $G^{\prime}=0.513 \mathrm{MPa}$, and loss modulus equal to $G^{\prime \prime}=0.6156 \mathrm{MPa}$. Based on a study by Chang et al. (1998) [7], the effective loss factor of the viscoelastic dampers assembly $\eta_{v-b}$ is given by equation (1) where $\frac{N_{\mathrm{B}}}{K_{v}}$ is the ratio of bracing to damper stiffness that is assumed to be 40 .

$\eta_{v-b}=\frac{\frac{K_{b}}{K_{v}}}{\eta_{v}^{z}+\frac{K_{b}}{K_{v}}+1} \eta_{v}$

The damping ratio of $i$-th mode of the structure is also obtained by the research carried out by Chang et al. (1992, 1995) [8, 9], equation (2), where $\omega_{i}$ and $\omega_{s i}$ are the natural frequencies of the structure without and with the dampers in terms of ( $\mathrm{rad} / \mathrm{s})$ respectively. In this equation, the damping ratio was assumed to be $15 \%$, which lead to $\omega_{s i}$ to be 1.167 times $\omega_{i}$. Chang et al. (1998) [7] provided the equations (3), (4), and (5), where the viscoelastic damper stiffness is $K_{v}$, the maximum nonlinear displacement of each damper is $\Delta_{\max }$, the $K_{v-b}$ is the stiffness of the damper system with braces, and $h_{s}$ is the height of each floor which is equal to 3 meters. Assuming the use of 2 layers of viscoelastic material and maximum allowable strain of viscoelastic material equal to $150 \%$, its area is calculated by equation (5), where $h$ is the thickness of viscoelastic material equal to $3 \mathrm{~cm}, N$ is the number of dampers on each floor, and $n$ is the number of viscoelastic material layers.

$$
\begin{aligned}
& \xi_{i}=\frac{\eta_{v-b}}{2}\left(1-\frac{\omega_{i}^{2}}{\omega_{s i}^{2}}\right) \\
& K_{v}=\frac{\left[\left(1+1_{v}^{2}\right)+\frac{K_{b}}{K_{v}}\right]\left[1+\eta_{v-b}^{2}\right]}{\frac{K_{b}}{K_{v}}\left(1+\eta_{v}^{2}\right)} K_{v-b} \\
& \Delta_{\max }=\frac{15}{1000} h_{s} \\
& A=\frac{K_{v} h}{N n G}
\end{aligned}
$$




\section{Investigating viscoelastic damper behavior under near-field earthquakes}

This study was carried out on a two-dimensional eight-story steel residential building, in which viscoelastic dampers are used. This structure contains three spans, each of them is 5 meters in length and the height of floors is 3 meters (Fig. 2). The gravity load of this structure consists of dead and live loads, is applied to the structure before lateral loading. The earthquake records considered in this study are presented in Table 1. These earthquakes have a pulse-like behavior.

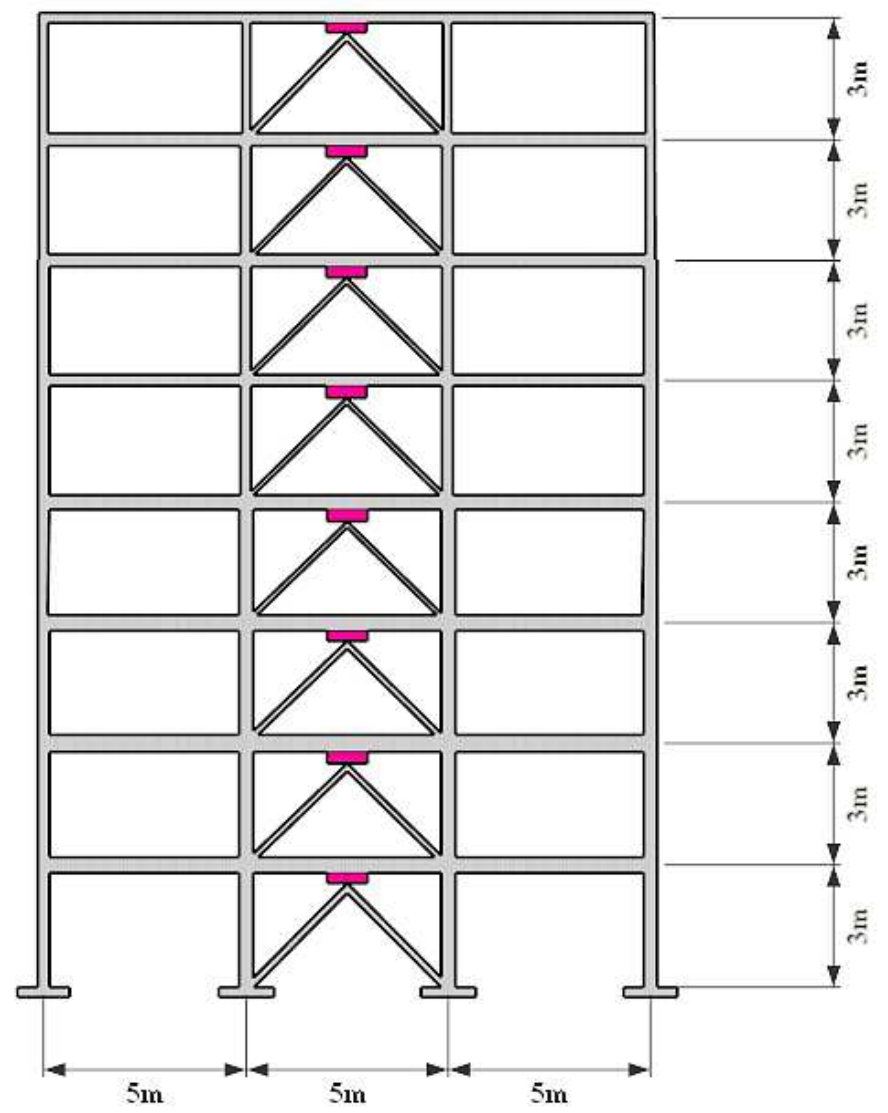

Fig. 2: Schematic of the studied structure.

Table 1: Specifications of the earthquakes investigated.

\begin{tabular}{|c|c|c|c|c|c|}
\hline Event & Year & Station & Magnitude & Mechanism & $\boldsymbol{V}_{\boldsymbol{s}}(\mathbf{m} / \mathbf{s})$ \\
\hline Duzce, Turkey & 1999 & Bolu & 7.14 & Strike Slip & 293.57 \\
\hline Darfield, New Zealand & 2010 & Riccarton High School & 7 & Strike Slip & 293 \\
\hline Loma Prieta, USA & 1989 & Gilroy Array & 6.93 & Reverse Oblique & 270.84 \\
\hline Parkfield, USA & 2004 & CA Fault Zone 1 & 6 & Strike Slip & 178.27 \\
\hline Parkfield, USA & 2004 & CA Fault Zone 7 & 6 & Strike Slip & 297.46 \\
\hline
\end{tabular}

\section{Investigating the amount of energy absorbed by viscoelastic dampers}

According to Fig. 3, after analyzing the considered structure using nonlinear time history analysis, viscoelastic dampers absorbed a significant amount of energy entered into the structure, which indicates that the dampers provided proper performance and high efficiency during considered earthquakes. For understanding the behavior of a single viscoelastic damper during near-field earthquakes, shear force-displacement diagrams for the viscoelastic damper on the last floor are given in Fig. 4. 


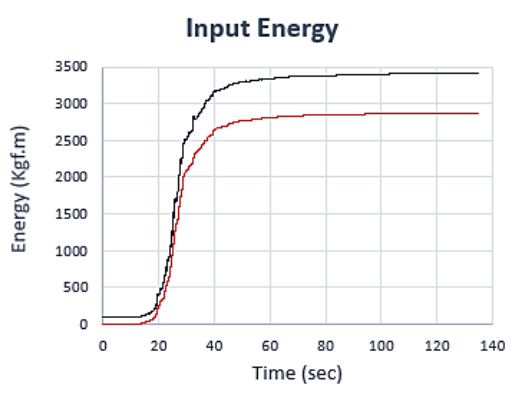

—Darfield —Damper Energy

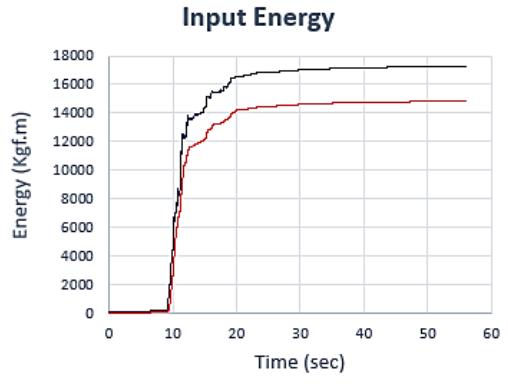

—Duzce —Damper Energy

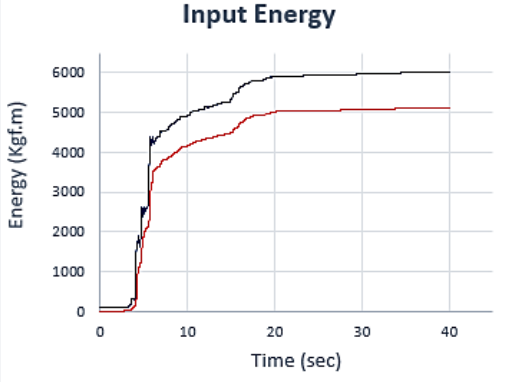

—Loma Prieta - Damper Energy

Fig. 3: Comparison between entered and absorbed energy into the structure.

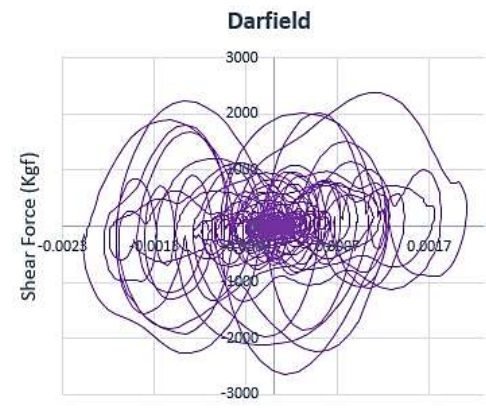

Displacement $(\mathrm{m})$

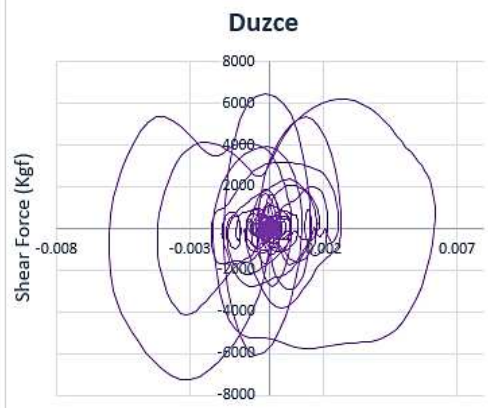

Displacement $(m)$

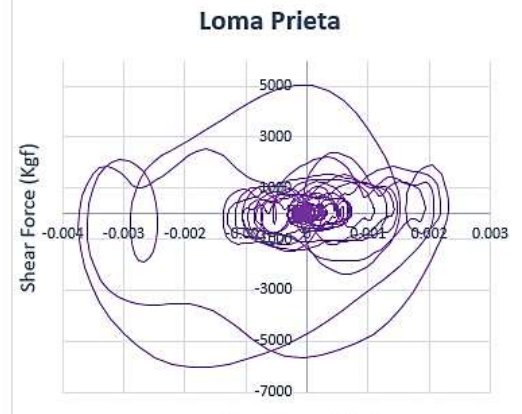

Displacement $(\mathrm{m})$

Fig 4: Shear force-displacement diagrams for the viscoelastic damper on the last floor.

\section{Investigating the performance of viscoelastic dampers under an earthquake with directivity feature}

Earthquake directivity is a phenomenon in which acceleration is applied more than usual in a particular direction during a certain period of time. It should be noted that if the period of the structure and the pulse period become close to each other, a force higher than expected value will apply to structure. The properties of the near-field earthquakes caused to form forces that were not previously seen in the design regulations. Therefore, after studying the impact of near-field earthquakes on structures, correction coefficients were added to the codes for this purpose Like Standard No. 2800 (2015) [10]. In order to investigate this issue, we studied the Parkfield 2004 earthquake. As shown in Fig. 5, two CA Fault Zone 1 and CA Fault Zone 7 stations have recorded time history of accelerations related to Parkfield 2004 earthquake. Ali Vatanshenas (2017) [11] stated that Parkfield 2004 is an earthquake with directivity feature and CA Fault Zone 1 received more acceleration than CA Fault Zone 7 during this earthquake.

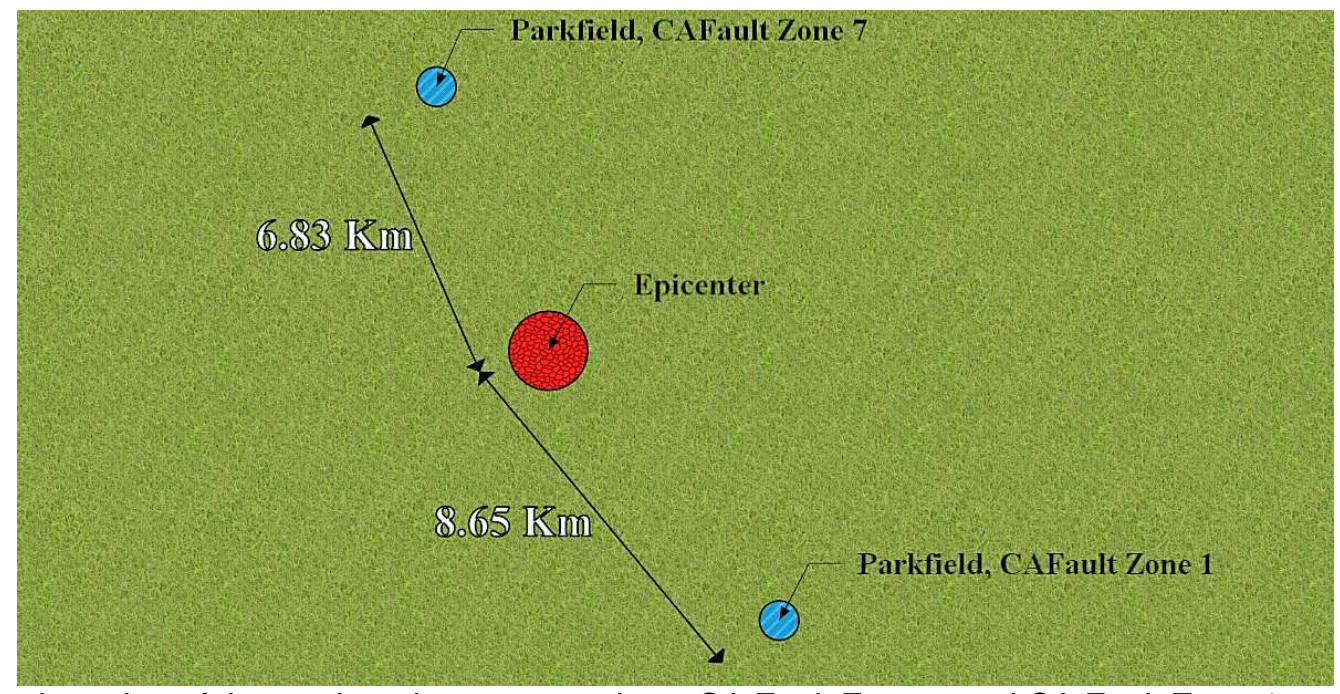

Fig. 5: Location of the earthquake center and two CA Fault Zone 7 and CA Fault Zone 1 stations. 
We plotted the acceleration-time (Fig. 6), the velocity-time (Fig. 7), and response accelerationperiod graphs (Fig. 8) for two stations and compared them with each other. As shown in Fig. 6, more acceleration is recorded at CA Fault Zone 1 Station. Fig. 7 also shows the pulse-like behavior in the velocity time history related to CA-Fault Zone 1. Also, in Fig. 8, a significant difference was observed between the spectral acceleration responses of these two stations for certain periods, in such a way that the acceleration applied to existing structures on the side of the CA Fault Zone 1 station was several times that of the other side. According to the reasons given for Figs. 6, 7, and 8, we found that the Parkfield 2004 earthquake along the CA Fault Zone 1 station has a directivity feature.

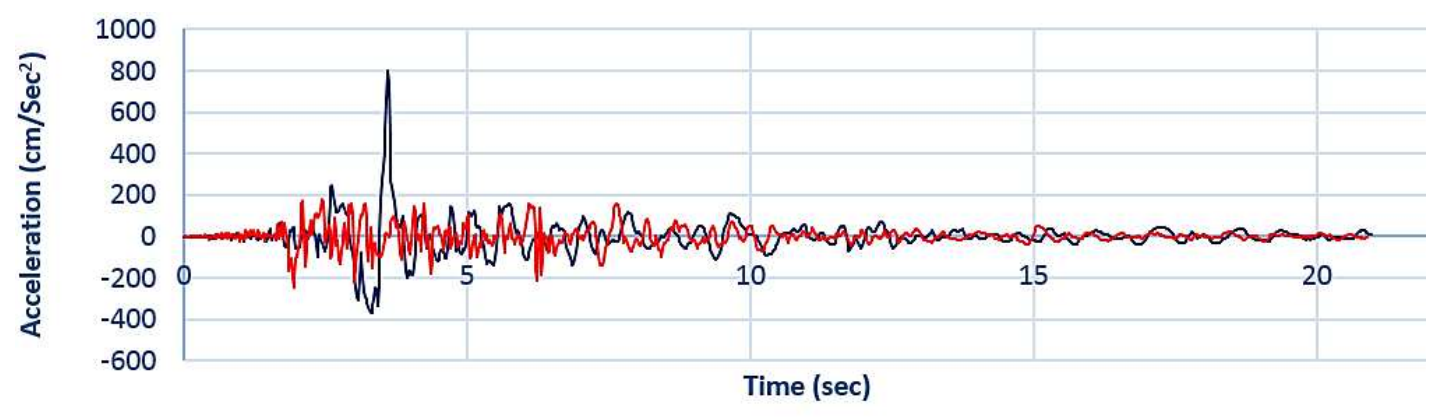

- CA Fault Zone 1 Channel 360 CA Fault Zone 7 Channel 360

Fig. 6: Acceleration time history of the two Parkfield 2004 earthquake stations.

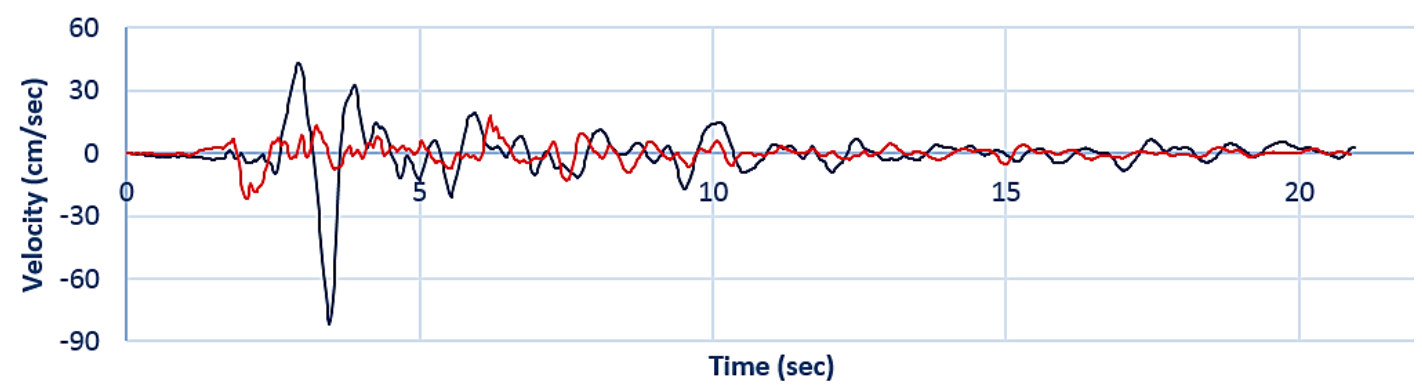

CA Fault Zone 1 Channel 360 CA Fault Zone 7 Channel 360

Fig. 7: Velocity time history of the two Parkfield 2004 earthquake stations.

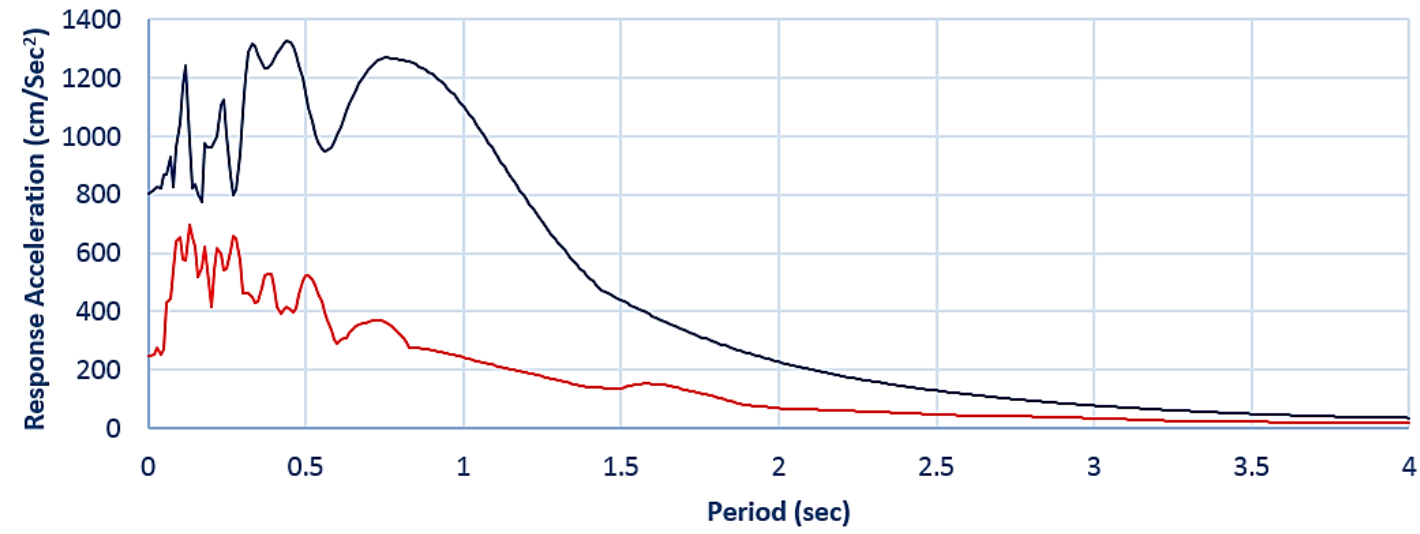

-CA Fault Zone 1 Channel 360 CA Fault Zone 7 Channel 360

Fig. 8: Spectral acceleration response related to two Parkfield 2004 Earthquake Stations.

To find the most critical angle of force applied to the structure due to the earthquake directivity, we plotted the spectral acceleration response diagrams of the CA Fault Zone 1 station, for each 10-degree rotation of the horizontal acceleration components perpendicular to each other which are recorded by this station (Fig. 9). In fact, by doing this, instead of turning the structure, we rotated the acceleration components. Considering that the period of the first mode of the structure under study is 
1.31 seconds, we found the maximum response acceleration corresponding to this period according to Fig. 9, which was $30^{\circ}$. In order to compare the performance of viscoelastic damper under the earthquake with directivity feature in two stations located on the side of directivity of the earthquake and without directivity, the structure under study was subjected to the acceleration time history of 30 degrees rotated (Fig. 10) and we compared the base shear (Fig. 11), input energy and dissipated energy by viscoelastic dampers (Fig. 12) for these two stations. After reviewing and comparing the base shear-time diagram for two Parkfield 2004 earthquake stations, it was observed that if the structure is built in a direction where directivity occurs, a large and significant force must be tolerated relative to the direction that directivity does not occur. According to Fig. 12, the directivity phenomenon leads to generate more input energy to the structure. But, it was observed that the viscoelastic damper in both cases of directivity and lack of directivity showed a proper performance in absorption and dissipation of the input energy.

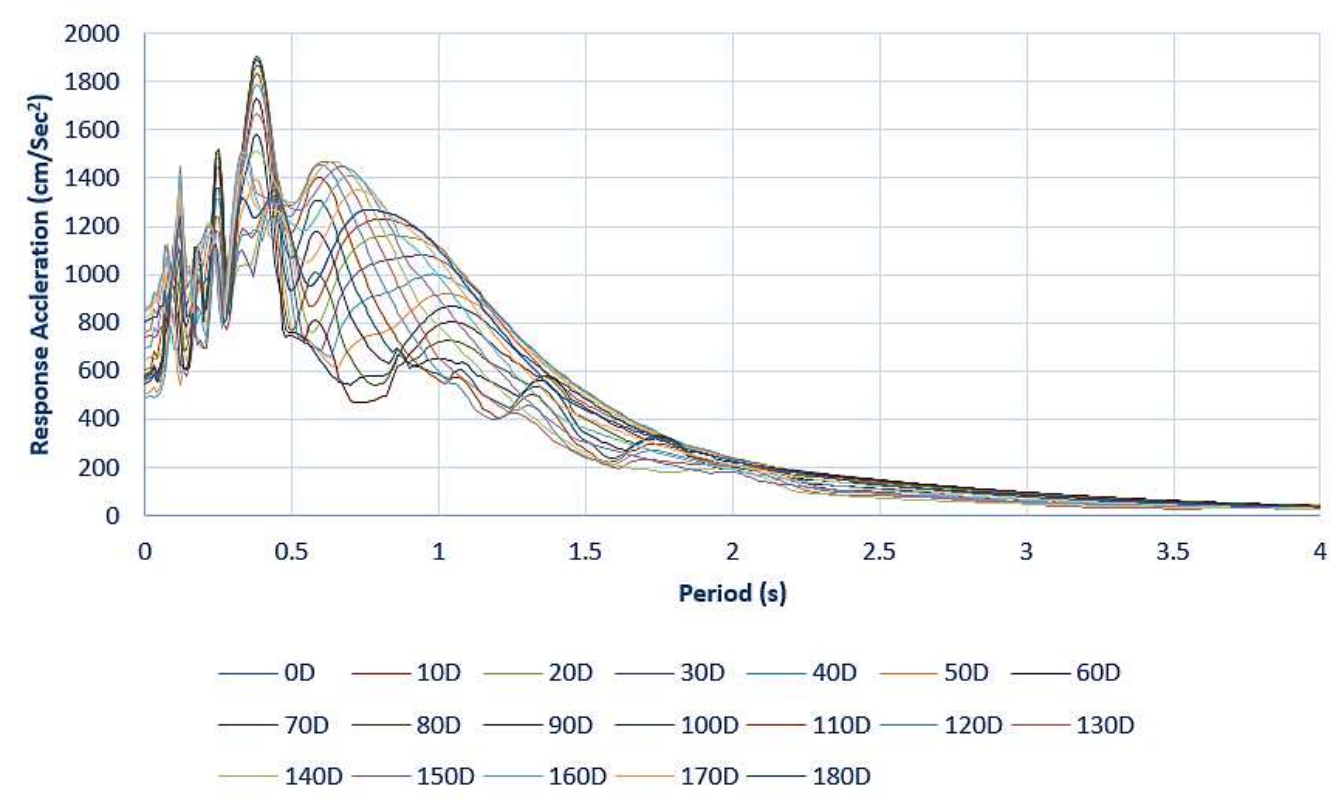

Fig. 9: Spectral acceleration response diagrams after rotation.

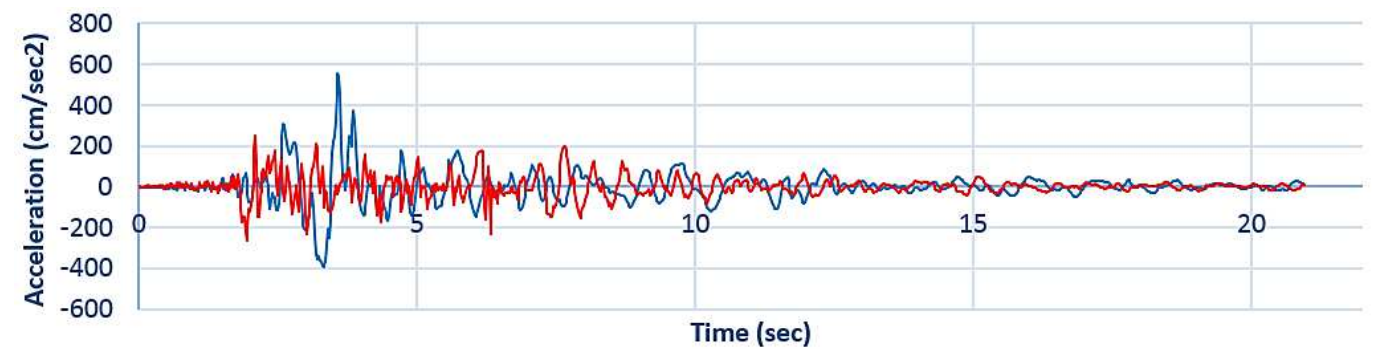

- CA Fault Zone 1 (30D) -CA Fault Zone 7 (30D)

Fig. 10: Acceleration time history of two stations after 30 degrees of rotation.

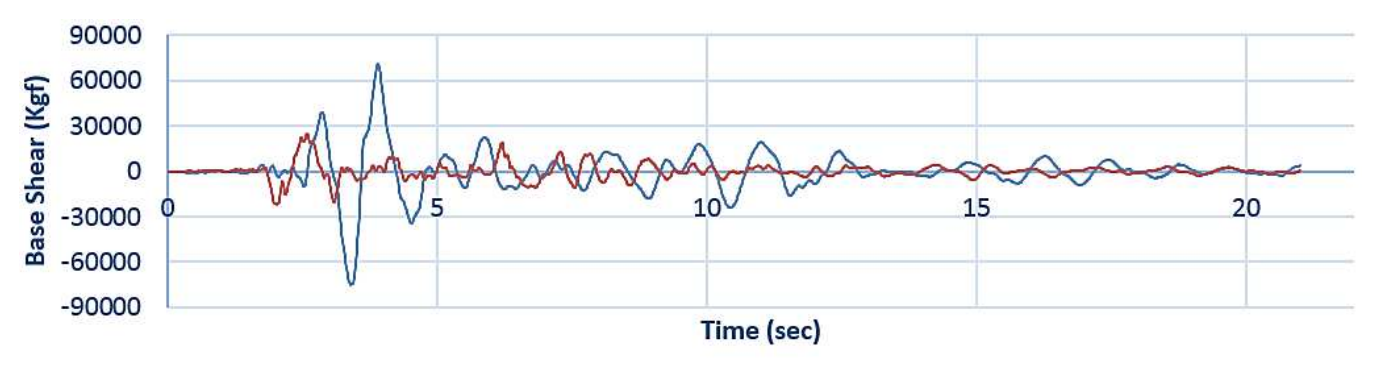

- CA Fault Zone 1 (30D) - CA Fault Zone 7 (30D)

Fig. 11: Comparison of the base shear of the structure after rotation of acceleration time history. 


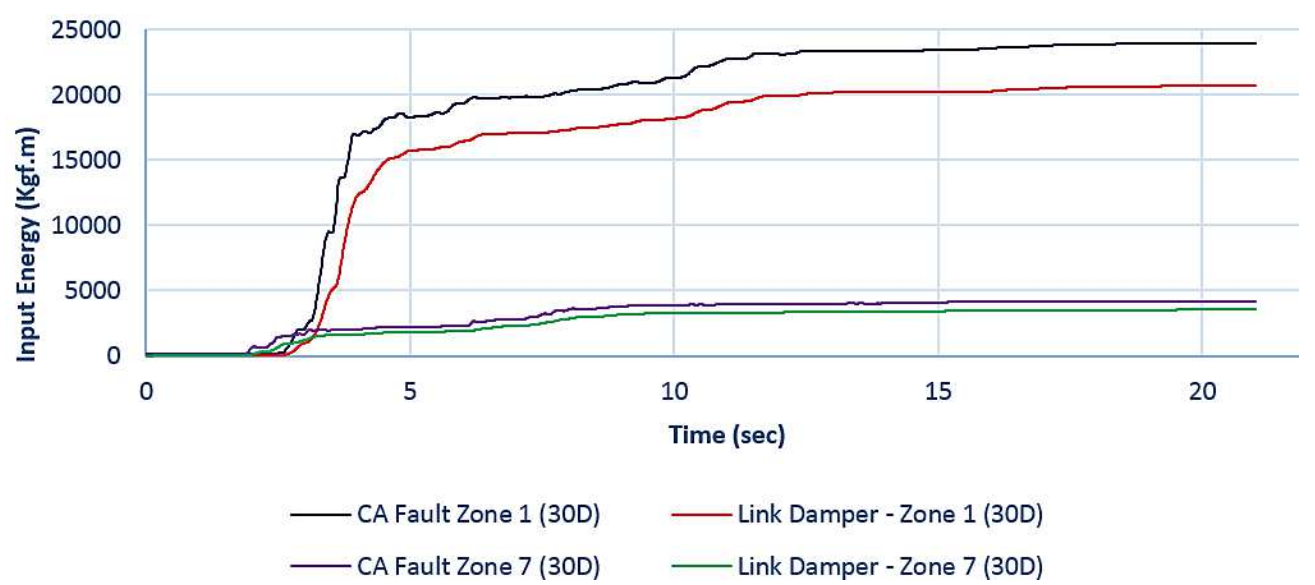

Fig. 12: Comparison of the values of input and dissipated energy by viscoelastic dampers.

\section{Conclusion}

After examining the behavior of viscoelastic damper under near-field earthquakes with directivity feature, it was observed that the directivity phenomenon leads to create higher acceleration, base shear, and input energy to the structure. It was observed that viscoelastic dampers in both cases of with and without directivity absorbed the significant amounts of input energy, therefore, are considered as an appropriate option to control the vibrations of the structure under the near-field earthquakes.

\section{References}

[1] COX, K. E. - ASHFORD, S. A.: Characterization of large velocity pulses for laboratory testing. Pacific Earthquake Engineering Research Center, 2002.

[2] WANG, G. Q. - ZHOU, X. Y. - ZHANG, P. Z. - IGEL, H.: Characteristics of amplitude and duration for near fault strong ground motion from the 1999 Chi-Chi, Taiwan earthquake. Soil Dyn. Earthq. Eng, Vol. 22, Iss. 1, 2002, pp. $73-96$.

[3] BERTERO, V. V. - MAHIN, S. A. - HERRERA, R. A.: Aseismic design implications of near-fault san fernando earthquake records. Earthq. Eng. Struct. Dyn, Vol. 6, Iss. 1, 1978, pp. $31-42$.

[4] CHOPRA, A. K. - CHINTANAPAKDEE, C.: Comparing response of SDF systems to near-fault and far-fault earthquake motions in the context of spectral regions. Earthq. Eng. Struct. Dyn, Vol. 30, Iss. 12,2001 , pp. $1769-1789$.

[5] SOMERVILLE, P. G. - SMITH, N. F. - GRAVES, R. W. - ABRAHAMSON, N. A.: Modification of Empirical Strong Ground Motion Attenuation Relations to Include the Amplitude and Duration Effects of Rupture Directivity. Seismol. Res. Lett, Vol. 68, Iss. 1, 1997, pp.199-222.

[6] GHOBARAH, A.: Response of Structures to Near-Fault Ground Motion. $13^{\text {th }}$ World Conference on Earthquake Engineering, Iss. 1031, 2004.

[7] CHANG, K. C. - LIN, Y. Y. - LAI, M. L.: Seismic Analysis and Design of Structures with Viscoelastic Dampers. ISET Journal of Earthquake Technology, Vol. 35, Iss. 4, 1998, pp. 143 -166.

[8] CHANG, K. C. - SOONG, T. T. - OH, S. T. - LAI, M. L.: Effect of Ambient Temperature on Viscoelastically Damped Structure. Journal of Structural Engineering, ASCE, Vol. 118, Iss. 7, 1992, pp. 1955 - 1973.

[9] CHANG, K. C. - SOONG, T. T. - OH, S. T. - LAI, M. L.: Seismic Behavior of Steel Frame with Added Viscoelastic Dampers. Journal of Structural Engineering, ASCE, Vol. 121, Iss. 10, 1995, pp. $1418-1426$.

[10] Iranian code of practice for seismic resistant design of buildings standard (4th ed.), 2015, Tehran: BHRC.

[11] VATANSHENAS, A.: Investigation of PTMD system affected by Parkfield near-field Earthquake. Journal of Modern Applied Science, Vol. 11, Iss. 4, 2017, pp. 70 - 79. 